\title{
Isthmic Papillary Thyroid Carcinoma Presents a Unique Pattern of Central Lymph Node Metastasis
}

This article was published in the following Dove Press journal:

Cancer Management and Research

\author{
Liguang Zhou ${ }^{1,2}$ \\ Chao $\mathrm{Gao}^{3}$ \\ Haipeng $\mathrm{Li}^{4}$ \\ Weili Liang $\left(\mathbb{D}^{3}\right.$ \\ Qingdong Zeng ${ }^{3}$ \\ Bo Chen ${ }^{3}$ \\ 'Department of Ultrasound, Shandong \\ Provincial Hospital Affiliated to Shandong \\ University, Jinan, People's Republic of \\ China; ${ }^{2}$ Department of Ultrasound, \\ Shandong Provincial Hospital Affiliated to \\ Shandong First Medical University, Jinan, \\ People's Republic of China; ${ }^{3}$ Department \\ of Thyroid Surgery, General Surgery, Qilu \\ Hospital, Shandong University, Jinan \\ 2500 12, People's Republic of China; \\ ${ }^{4}$ Department of General Surgery, Cao \\ County People's Hospital, Heze, People's \\ Republic of China
}

\begin{abstract}
Purpose: Treatment protocols for occult central lymph node metastasis (LNM) associated with papillary thyroid cancer (PTC) located in the isthmus are debatable. We aimed to analyze the pattern of occult central LNM in isthmic PTC, including risk factors for bilateral paratracheal LNM.
\end{abstract}

Patients and Methods: Consecutive patients with PTC were recruited to this study. All patients underwent total thyroidectomy and prophylactic bilateral central neck dissection. The clinicopathologic features and distribution of central LNM were compared between the two groups, and risk factors for bilateral paratracheal LNM were analyzed.

Results: A total of 174 patients with PTC were enrolled in this study, of whom 87 patients had isthmic PTC (study group) and 87 patients had lobe-originating PTC (control group). The two groups had comparable demographics and tumor features. There were higher frequencies of pretracheal LNM $(\mathrm{P}=0.001)$ and bilateral paratracheal LNM $(\mathrm{P}=0.002)$ in the isthmic PTC group. Bilateral paratracheal LNM was significantly associated with age $<55$ years $(\mathrm{P}=0.037)$, capsular invasion $(\mathrm{P}=0.034)$, tumor location (isthmus) $(\mathrm{P}<0.001)$, $B R A F$ gene mutation $(\mathrm{P}=0.013)$, and pretracheal LNM $(\mathrm{P}<0.001)$. Isthmus location (odds ratio [OR]: 4.116, 95\% confidence interval [CI]: $1.264-13.433, \mathrm{P}=0.019$ ) and pretracheal LNM (OR: 3.422, 95\% CI: 1.214-9.642, $\mathrm{P}=0.020$ ) were independent risk factors for bilateral paratracheal LNM.

Conclusion: Because of its unique anatomic location, isthmic PTC differs from PTC in the lobe with respect to pretracheal and bilateral paratracheal LNM, even in patients of comparable age, sex, tumor size, extrathyroidal extension, $B R A F$ mutation, and pathologic TNM staging. The isthmus location was found to be an independent risk factor for bilateral paratracheal LNM. This information may contribute to the development of an appropriate surgical protocol for isthmic PTC.

Keywords: tumor location, bilateral paratracheal sub-compartments, risk factors

\section{Introduction}

Papillary thyroid cancer (PTC), which accounts for $>90 \%$ of all thyroid malignancies, is a differentiated carcinoma with a relatively good prognosis and low mortality rate. ${ }^{1}$ However, PTC is prone to central lymph node metastasis (LNM), which is associated with a high prevalence of locoregional recurrence. ${ }^{2}$ In many patients, central LNM is undetected by preoperative imaging and intraoperative palpation, accounting for a clinically node-negative (cN0) group. ${ }^{3}$ The role and extent of prophylactic central neck dissection (CND) in patients with PTC remains controversial because of a lack of substantial evidence for benefit and the potential morbidity associated with the procedure. ${ }^{4}$ 
Although the isthmus makes up only a small proportion of the thyroid, PTC located in the isthmus is not uncommon, with a prevalence of $12.3 \%$ reported by Lim et $\mathrm{al}^{5}$ and $10.2 \%$ by Chang et al. ${ }^{6}$ Isthmic PTC has a unique anatomic location, and its blood supply and lymphatic drainage differ from those of lobe-originating PTC. ${ }^{7}$ Sometimes, the isthmus presents with the fibers of Soemmerring's muscle. This is a small strap of muscle arising from the hyoid bone and inserting partly on the thyroid cartilage and partly on the isthmus. Such presentation can lead to a reliable diagnosis of extrathyroidal extension (ETE) in lobe-originating PTC, but not in isthmic PTC. ${ }^{8,9}$ In addition, some authors have reported that isthmic PTC has a higher central LNM rate compared with tumors in the lobe. ${ }^{10,11}$ Despite this evidence, the American Thyroid Association has not provided specific guidelines for managing isthmic PTC. ${ }^{3}$ Indeed, little is currently known about the pattern and predictors of occult central LNM in isthmic PTC. Therefore, various groups have applied different treatment protocols for occult central LNM, including isthmectomy alone or with limited $\mathrm{CND},{ }^{7,10}$ unilateral $\mathrm{CND},{ }^{5,12,13}$ and bilateral $\mathrm{CND}{ }^{14}$ Lymph node dissection in bilateral paratracheal subcompartments is more complicated and hazardous than in unilateral central compartment owing to the risk of bilateral recurrent laryngeal nerve injury and damage to the parathyroid glands.

The goals of this study were: 1) to explore the pattern of occult central LNM in isthmic PTC versus lobe-originating PTC; and 2) to determine whether the isthmus location represents an additional risk factor for bilateral paratracheal LNM, which would help to inform appropriate treatment for occult central LNM in patients with isthmic PTC.

\section{Patients and Methods}

\section{Patients}

Consecutive patients with PTC being treated at our hospital between November 2016 and October 2019 were considered to the analysis. Approval for this study was obtained from the ethics committee of Qilu Hospital of Shandong University which compliance with the Declaration of Helsinki and a statement of written informed consent from all participants is required. All patients were diagnosed on high-resolution ultrasonography and in most cases, disease was confirmed by fineneedle aspiration. Computed tomography was performed in each patient for a detailed preoperative evaluation of nodules and the central lymph nodes. All patients underwent total thyroidectomy and bilateral CND, with all procedures performed by the same surgeon. Exclusion criteria included multiple malignant carcinomas, cN1 PTC, other pathologic types of thyroid cancer, recurrent disease, previous neck surgery or a history of irradiation involving the neck region, and thyroid lobectomy or unilateral CND.

Patient data were extracted from medical records and analyzed for various clinicopathologic factors, including demographics, tumor features, and postoperative pathologic details.

\section{Surgical Procedures}

Operations were performed according to the method described by Koo et al. ${ }^{15}$ We divided the central compartment into the prelaryngeal (Delphian), pretracheal, and right and left paratracheal sub-compartments following recommendations previously reported by Orloff and Kuppersmith. ${ }^{16}$ Prelaryngeal lymph nodes were bounded superiorly by the inferior border of the hyoid bone and inferiorly by the cricoid cartilage. Pretracheal lymph nodes were bounded superiorly by the inferior border of the gland, inferiorly by the innominate artery, and posteriorly by the trachea. Ipsilateral/contralateral paratracheal lymph nodes were demarcated laterally by the carotid artery and medially by the trachea.

\section{Pathology Examination of Lymph Nodes in Sub-Compartments}

We submitted lymph nodes to histology examination according to the protocol described by Haglund and colleagues. ${ }^{17}$ Upon removal, the thyroid and CND specimens (including fat tissue in sub-compartments) were sent directly to the Pathology Department of our hospital for gross diagnostic evaluation. First, macroscopically identified lymph nodes were dissected out of the fat, then bisected if they were $\geq 5 \mathrm{~mm}$ in greatest dimension. The only difference was that we selected patients with $\mathrm{CNO}$ in the present study. The lymph nodes in each sub-compartment were not too large, so multiple-level sectioning (which can improve the diagnostic accuracy of larger lymph nodes ${ }^{17}$ ) was not adopted.

\section{BRAF Mutation Analysis}

Analyses of BRAF mutations were done in the Pathology Department of our hospital. DNA samples for molecular analyses were extracted from postoperative surgical 
specimens using the QIAamp ${ }^{\mathrm{TM}}$ DNA FFPE Tissue kit (Qiagen, Stanford, VA, USA) following manufacturer instructions.

\section{Definitions}

\section{PTC Located in the Isthmus}

We defined PTC located in the isthmus according to Lim et al. ${ }^{5}$ Briefly, we first drew virtual lines perpendicularly from the most lateral point of the trachea to the surface of the skin on both sides. Next, we designated the center point of the tumor as the intersection of its longest and shortest diameters. If the center point of the tumor was located between the two virtual lines, it was deemed to be located in the isthmus (Figure 1).

\section{Extrathyroidal Extension and Capsular Invasion}

Extrathyroidal extension (ETE) is defined as tumor extension into the adjacent tissues, and subdivided into minimal and extensive ETE. ${ }^{9}$ Capsular invasion, which is a type of minimal ETE, is defined as microscopic invasion into the immediate perithyroidal soft tissues without attachment to the surrounding muscular components. ${ }^{18}$ In this study, ETE specifically refers to macroscopic invasion into the sternothyroid muscle (T3 tumors) and extensive invasion into the subcutaneous soft tissues, larynx, trachea, esophagus, or recurrent laryngeal nerve (T4a tumors).

\section{TNM Staging}

Pathologic tumor staging was determined in accordance with the American Joint Committee on Cancer staging system (8th edition). ${ }^{19}$

\section{Statistical Analysis}

SPSS Statistics 20.0 (SPSS, Inc., Chicago, IL) was used for data analysis and statistical significance was defined as $\mathrm{P}<0.05$. Continuous variables are shown as means \pm standard deviation, and were analyzed using $t$-tests. Categorical variables were compared using the $\chi^{2}$ test or Fisher's exact test. Logistic regression was used for multivariate analysis.

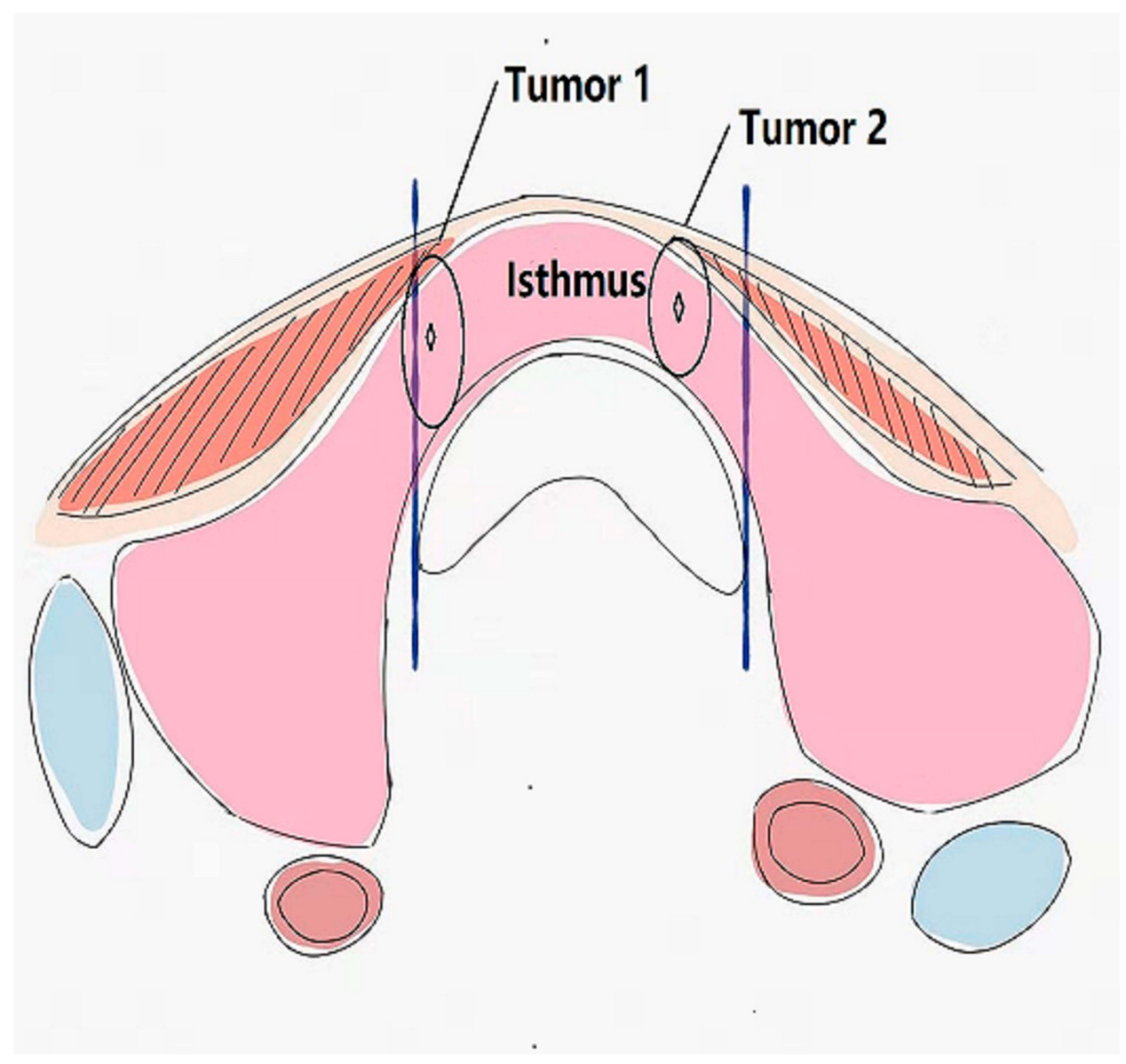

Figure I Papillary thyroid cancer located in the isthmus. Papillary thyroid cancer was defined as being located in the isthmus if the center point of the tumor was located between two virtual lines (both Tumor I and 2 were regarded as isthmic tumors). 


\section{Results}

\section{Demographic and Pathologic Features}

A total of 174 patients with PTC were enrolled in this study and successfully underwent total thyroidectomy and bilateral CND, of whom 32 were men and 142 were women. Patient age ranged from 19 to 75 years, with a median of 49 years. A total of 87 patients had isthmic PTC, while 87 patients with PTC located in the right or left lobe formed the non-isthmus control group. The demographics and tumor features of the two group are shown in Table 1. There were no significant differences between two groups in terms of sex, age, body mass index, tumor size, ETE, concomitant thyroiditis, pathologic subtype, BRAF gene mutation, or pathologic (p)TNM staging (all $\mathrm{P}>0.05$ ). However, capsular invasion was more frequent in the isthmus group than in the control group $(\mathrm{P}<0.001)$.

\section{Pattern of Central LNM}

The overall central LNM rate was $63.2 \%(55 / 87)$ in the isthmic group and $49.4 \%$ (43/87) in the control group. Despite this numeric difference between the two groups, the difference was not statistically significant $(\mathrm{P}=0.067)$. Regarding the distribution of central LNM, pretracheal LNM was significantly more frequent in the isthmus group compared with the control group (35.6\% vs $13.8 \%, \mathrm{P}=0.001$ ). Prelaryngeal LNM trended toward a higher rate in the isthmic PTC group, but the difference was not significant $(20.7 \%$ vs $13.8 \%, \mathrm{P}=0.229)$. The overall rate of paratracheal LNM was comparable between the two groups (32.2\% vs $31.0 \%, \mathrm{P}=0.870)$. However, bilateral paratracheal LNM was more significantly more frequent in the isthmus group compared with the control group $(24.1 \%$ vs $6.9 \%, P=0.002)$. In contrast, the control group had a significantly higher frequency of unilateral paratracheal LNM (24.1 vs $8.0 \%, \mathrm{P}=0.004)$ (Table 2).

\section{Risk Factors for Bilateral Paratracheal LNM in PTC}

On univariate analysis, bilateral paratracheal LNM was significantly associated with age $<55$ years $(\mathrm{P}=0.037)$, capsule invasion ( $\mathrm{P}=0.034)$, tumor location (isthmus) $(\mathrm{P}<0.001)$, $B R A F$ gene mutation $(\mathrm{P}=0.013)$, and pretracheal LNM $(\mathrm{P}<$ 0.001), while sex, tumor size, ETE, pathology subtype, Hashimoto's thyroiditis, pTNM staging, and prelaryngeal LNM were comparable between the two groups (all P > 0.05) (Table 3). Isthmus location (odds ratio [OR]: 4.116, 95\% confidence interval $[\mathrm{CI}]: 1.264-13.433, \mathrm{P}=0.019)$ and pretracheal LNM (OR: 3.422, 95\% CI: 1.214-9.642, P =
Table I Comparision of the Baseline Demographics and Pathologic Features Between the Isthmus and Control Groups

\begin{tabular}{|c|c|c|c|}
\hline Variable & $\begin{array}{l}\text { Isthmus Group } \\
(\mathrm{n}=\mathbf{8 7})\end{array}$ & $\begin{array}{l}\text { Control Group } \\
(n=87)\end{array}$ & $P$ value \\
\hline $\begin{array}{l}\text { Sex } \\
\qquad \text { Male } \\
\text { Female }\end{array}$ & $\begin{array}{l}14 \\
73\end{array}$ & $\begin{array}{l}18 \\
69\end{array}$ & 0.434 \\
\hline $\begin{array}{l}\text { Age } \\
\qquad 55 \text { years } \\
\geq 55 \text { years }\end{array}$ & $\begin{array}{l}58 \\
29\end{array}$ & $\begin{array}{l}53 \\
34\end{array}$ & 0.430 \\
\hline $\begin{array}{l}\text { Body mass } \\
\text { index, } \mathrm{kg} / \mathrm{m}^{2}\end{array}$ & $25.4 \pm 4.1$ & $25.1 \pm 3.8$ & 0.617 \\
\hline $\begin{array}{l}\text { Tumor size } \\
\leq 10 \mathrm{~mm} \\
>10 \mathrm{~mm}\end{array}$ & $\begin{array}{l}31 \\
56\end{array}$ & $\begin{array}{l}29 \\
58\end{array}$ & 0.750 \\
\hline $\begin{array}{l}\text { Capsular } \\
\text { invasion, yes/no }\end{array}$ & $49 / 38$ & $22 / 65$ & $<0.001$ \\
\hline $\begin{array}{l}\text { Extrathyroidal } \\
\text { extension, yes/no }\end{array}$ & $19 / 68$ & $11 / 76$ & 0.108 \\
\hline $\begin{array}{l}\text { Intraglandular } \\
\text { dissemination, yes/ } \\
\text { no }\end{array}$ & $11 / 76$ & $6 / 81$ & 0.202 \\
\hline $\begin{array}{l}\text { Concomitant } \\
\text { thyroiditis, yes/no } \\
\text { Pathologic subtype }\end{array}$ & $22 / 65$ & $29 / 58$ & 0.244 \\
\hline $\begin{array}{l}\text { Classical } \\
\text { Non-classical }\end{array}$ & $\begin{array}{l}59 \\
28\end{array}$ & $\begin{array}{l}54 \\
33\end{array}$ & 0.427 \\
\hline $\begin{array}{l}\text { BRAF gene } \\
\text { mutation, yes/no }\end{array}$ & $65 / 22$ & $61 / 26$ & 0.497 \\
\hline $\begin{array}{l}\text { PTNM stage, I/II/ } \\
\text { III/IV }\end{array}$ & $65 / 4 / 12 / 6$ & $59 / 3 / 21 / 4$ & 0.349 \\
\hline
\end{tabular}

Notes: Values are $n$ or mean \pm standard deviation. Significant values are shown in bold. Abbreviation: PTNM stage, pathologic TNM stage.

0.020) were independent risk factors for bilateral paratracheal LNM on multivariate logistic regression analysis (Table 4).

\section{Discussion}

In this study, most clinicopathologic factors such as sex, age, body mass index, tumor size, ETE, concomitant thyroiditis, pathologic subtype, $B R A F$ gene mutation, and pTNM staging were comparable between patients with isthmic PTC and those with non-isthmus, lobe-originating PTC. This is partly because the patients enrolled in this study were required to have surgical indications for total thyroidectomy and bilateral CND, which excluded patients with noninvasive, small PTC in a unilateral lobe who needed only a lobectomy and unilateral CND.

However, previous studies have reported a higher central LNM rate in isthmic compared with lobe-originating PTC. ${ }^{10,11,20}$ In these studies, patients with isthmic PTC 
Table 2 Distribution of Cervical Lymph Node Metastasis in the Isthmus and Control Groups

\begin{tabular}{|l|l|l|l|}
\hline $\begin{array}{l}\text { Distribution, } \\
\mathbf{n}(\%)\end{array}$ & $\begin{array}{l}\text { Isthmus Group } \\
(\mathbf{n}=\mathbf{8 7})\end{array}$ & $\begin{array}{l}\text { Control Group } \\
(\mathbf{n}=\mathbf{8 7})\end{array}$ & P value \\
\hline Central LNM & $55(63.2)$ & $43(49.4)$ & 0.067 \\
\hline $\begin{array}{l}\text { Pretracheal } \\
\text { LNM }\end{array}$ & $\mathbf{3 I}(35.6)$ & $\mathbf{1 2 ( 1 3 . 8 )}$ & $\mathbf{0 . 0 0 I}$ \\
Prelaryngeal LNM & $18(20.7)$ & $12(13.8)$ & 0.229 \\
Paratracheal LNM & $28(32.2)$ & $27(31.0)$ & 0.870 \\
\hline Unilateral & $\mathbf{7 ( 8 . 0 )}$ & $\mathbf{2 1}(\mathbf{2 4 . 1 )}$ & $\mathbf{0 . 0 0 4}$ \\
Bilateral & $\mathbf{2 I ( 2 4 . 1 )}$ & $\mathbf{6 ( 6 . 9 )}$ & $\mathbf{0 . 0 0 2}$ \\
\hline
\end{tabular}

Note: Significant values are shown in bold.

Abbreviation: LNM, lymph node metastasis.

had a higher frequency of ETE and multifocality, which were predictors of central LNM and also associated with contralateral paratracheal $\mathrm{LNM}^{10,11,20,21}$ Therefore, we cannot know whether the higher central LNM rate in isthmic PTC is due to a higher frequency of ETE and multifocality or to the unique anatomic location of isthmic PTC. To determine this, we have explored the pattern of LNM in isthmic PTC in two groups with similar basic data, which seems likely to give more meaningful results.

In our study, the isthmus group had a higher frequency of capsular invasion than the control group $(56.3 \%$ vs $25.3 \%, \mathrm{P}<0.001$ ), which is consistent with previous results. ${ }^{10,22} \mathrm{~A}$ high frequency of capsular invasion may be attributable to the thin shape of the isthmus, ${ }^{18}$ and appears to be independent of tumor size because it has also been reported to be common in isthmus microcarcinomas. ${ }^{20}$ According to our study, only the higher frequency of capsular invasion may have little effect on central LNM. Recently, Li et al also reported no difference in central LNM between PTC patients with and without capsular invasion. ${ }^{23}$

This study found an occult central LNM rate of $63.2 \%$ in the isthmus group, which is within the reported range from previous series (29.6-71.1\%). ${ }^{12,14,22,24,25}$ Although isthmic PTC was more prone to central LNM than the control group, there was no significant difference between the two groups (63.2\% vs $49.4 \%, P=0.067)$. Similar findings have been reported in a previous study, in which the isthmic PTC group trended toward having a higher rate of central LNM $(\mathrm{P}=0.09)$, but a significant difference was not shown because of comparable multifocal disease $(\mathrm{P}=0.08)$ and ETE $(\mathrm{P}=0.09)$ between the isthmus and non-isthmus groups. $^{24}$
Table 3 Univariate Analysis of the Clinical Pathologic Factors Associated with Bilateral Paratracheal LNM in Papillary Thyroid Cancer

\begin{tabular}{|c|c|c|c|c|c|}
\hline \multirow[t]{2}{*}{ Variable } & \multicolumn{3}{|c|}{$\begin{array}{l}\text { Number and } \\
\text { Percentage of } \\
\text { Patients with } \\
\text { Bilateral } \\
\text { Paratracheal LNM }\end{array}$} & \multirow[t]{2}{*}{$\chi^{2}$} & \multirow[t]{2}{*}{$P$ value } \\
\hline & Yes & No & $M$ rate & & \\
\hline \multicolumn{6}{|l|}{ Age } \\
\hline$<55$ years & 22 & 89 & $19.8 \%$ & 4.329 & 0.037 \\
\hline$\geq 55$ years & 5 & 58 & $7.9 \%$ & & \\
\hline \multicolumn{6}{|l|}{ Sex } \\
\hline Female & 20 & 122 & $14.1 \%$ & 1.209 & 0.272 \\
\hline Male & 7 & 25 & $21.9 \%$ & & \\
\hline \multicolumn{6}{|l|}{ Tumor size } \\
\hline$\leq 10 \mathrm{~mm}$ & 9 & 51 & $15.0 \%$ & 0.019 & 0.891 \\
\hline$>10 \mathrm{~mm}$ & 18 & 96 & $15.8 \%$ & & \\
\hline \multicolumn{6}{|l|}{ Capsule invasion } \\
\hline Yes & 16 & 55 & $22.5 \%$ & 4.506 & 0.034 \\
\hline No & 11 & 92 & $10.7 \%$ & & \\
\hline \multicolumn{6}{|l|}{$\begin{array}{l}\text { Extrathyroidal } \\
\text { extension }\end{array}$} \\
\hline Yes & 8 & 22 & $26.67 \%$ & 3.437 & 0.064 \\
\hline No & 19 & 125 & $13.19 \%$ & & \\
\hline \multicolumn{6}{|l|}{ Tumor location } \\
\hline Isthmus & 22 & 55 & $28.6 \%$ & 17.955 & $<0.001$ \\
\hline Lobe & 5 & 92 & $5.2 \%$ & & \\
\hline \multicolumn{6}{|l|}{ Pathologic subtype } \\
\hline Classical & 16 & 97 & $14.16 \%$ & 0.453 & 0.501 \\
\hline Non-classical & 11 & 50 & $18.03 \%$ & & \\
\hline \multicolumn{6}{|l|}{$\begin{array}{l}\text { Hashimoto's } \\
\text { thyroiditis }\end{array}$} \\
\hline Yes & 7 & 44 & $13.73 \%$ & 0.177 & 0.674 \\
\hline No & 20 & 103 & $16.26 \%$ & & \\
\hline \multicolumn{6}{|l|}{ BRAF gene mutation } \\
\hline Yes & 25 & 102 & $19.7 \%$ & 6.230 & 0.013 \\
\hline No & 2 & 45 & $4.3 \%$ & & \\
\hline \multicolumn{6}{|l|}{ TNM staging } \\
\hline$I+I I$ & 20 & 111 & $15.3 \%$ & 0.025 & 0.874 \\
\hline III + IV & 7 & 36 & $16.3 \%$ & & \\
\hline \multicolumn{6}{|l|}{ Pretracheal LNM } \\
\hline Yes & 18 & 32 & $36.0 \%$ & 22.454 & $<0.001$ \\
\hline No & 9 & 115 & $7.3 \%$ & & \\
\hline \multicolumn{6}{|l|}{ Prelaryngeal LNM } \\
\hline Yes & 6 & 24 & $20.00 \%$ & 0.556 & 0.456 \\
\hline No & 21 & 123 & $14.6 \%$ & & \\
\hline
\end{tabular}

Note: Significant values are shown in bold.

Abbreviation: LNM, lymph node metastasis. 
Table 4 Multivariate Analysis of the Clinical Pathologic Factors Associated with Bilateral Paratracheal LNM in Papillary Thyroid Cancer

\begin{tabular}{|l|l|l|l|l|l|l|}
\hline Variable & $\boldsymbol{\beta}$ & SE & Wald & $\mathbf{P}$ & $\mathbf{E x p ( \beta )}$ & $\mathbf{9 5 \%} \mathbf{C l}$ \\
\hline Age $<55$ years & 0.282 & 0.516 & 0.300 & 0.584 & 1.326 & $0.483-3.644$ \\
Capsule invasion & 0.872 & 0.476 & 3.355 & 0.067 & 2.392 & $0.94 I-6.08 I$ \\
Isthmic tumor & $\mathbf{1 . 4 1 5}$ & $\mathbf{0 . 6 0 4}$ & $\mathbf{5 . 4 9 6}$ & $\mathbf{0 . 0 1 9}$ & $\mathbf{4 . 1 1 6}$ & $\mathbf{1 . 2 6 4 - 1 3 . 4 3 3}$ \\
BRAF gene mutation & 1.178 & 0.677 & 3.029 & 0.082 & 3.248 & $0.86 I-12.244$ \\
Pretracheal LNM & $\mathbf{1 . 2 3 0}$ & $\mathbf{0 . 5 2 9}$ & $\mathbf{5 . 4 1 5}$ & $\mathbf{0 . 0 2 0}$ & $\mathbf{3 . 4 2 2}$ & $\mathbf{1 . 2 1 4 - 9 . 6 4 2}$ \\
Constant & -5.313 & 1.546 & $\mathbf{I I . 8 0 8}$ & 0.001 & 0.005 & $1.214-9.642$ \\
\hline
\end{tabular}

Note: Significant values are shown in bold.

Abbreviations: $\beta$, regression coefficient; $\mathrm{Cl}$, confidence interval; $\operatorname{Exp}(\beta)$, odds ratio; LNM, lymph node metastasis; SE, standard error.

Although there was no significant difference in the overall central LNM rate in the current study, both pretracheal LNM and bilateral paratracheal LNM were significantly more frequent in the isthmus group compared with the control group (pretracheal LNM: $35.6 \%$ vs $13.8 \%, \mathrm{P}=0.001$; bilateral paratracheal LNM: $24.1 \%$ vs $6.9 \%, \mathrm{P}=0.002$ ), and only unilateral paratracheal LNM was more involved in the control group $(24.1 \%$ vs $8.0 \%$, $\mathrm{P}=0.004)$. Song et al also reported that pretracheal and bilateral paratracheal lymph nodes were more likely to be affected in patients with isthmic PTC, with involvement rates of $26.0 \%$ and $38.4 \%$, respectively. ${ }^{25}$ A limitation, however, was that the participants enrolled in their study included not only patients with cN0 but also those with $\mathrm{cN} 1$. The homogeneity of the patients in our study might contribute to a more reliable result. The exact pathophysiologic mechanism explaining the distribution and incidence of LNM in sub-compartments is unclear. A possible explanation is that the lymphatics from the isthmus drain more easily into the inferior pretracheal sub-compartment, and subsequently into the bilateral paratracheal subcompartment. ${ }^{20}$ As to prelaryngeal LNM, Lee et al previously reported it was significantly associated with isthmic PTC. ${ }^{26}$ In this study, the isthmus group trended toward a higher rate of prelaryngeal LNM, but there was no significant difference between two groups $(20.7 \%$ vs $13.8 \%, \mathrm{P}=0.229$ ), perhaps because the prelaryngeal subcompartment simultaneously receives afferent lymphatic drainage from the isthmus and thyroid lobes. ${ }^{13}$

To the best of our knowledge, little is currently known about whether an isthmic location of PTC is an independent risk factor for bilateral paratracheal LNM. Isthmus location has previously been reported to be predictor of central LNM, which was not found to contribute to the extent of CND for patients with cN0 disease. ${ }^{14,25,27,28}$ The same was true for the relationship between isthmic PTC and prelaryngeal LNM, as reported by Lee et al. ${ }^{26}$ And, as mentioned above, the data from most of these studies have been heterogeneous in terms of ETE, multifocality, and nodal status in the central compartment, ${ }^{14,25}$ which will have affected the accuracy of the results. In the current study, bilateral paratracheal LNM involvement was associated with age ( $<55$ years), capsular invasion, $B R A F$ gene mutation, pretracheal LNM, and tumor location in the isthmus. Isthmic location represented an independent risk factor for bilateral paratracheal LNM on multivariate analysis.

Our findings indicate that bilateral CND is an appropriate surgical procedure for occult central LNM of isthmic PTC. Surgical protocols including limited or ipsilateral CND can reduce the risks of bilateral recurrent laryngeal nerve injury and damage to the parathyroid glands, but their disadvantages are obvious from treatment effectiveness evaluations. In a large retrospective study that included data from 1810 patients with isthmic PTC over a 20 -year period, isthmusectomy alone was suitable for just 19 patients (1\%) with small, noninvasive, and well-differentiated PTC in the isthmus. ${ }^{7}$ In addition, limited or ipsilateral CND for patients with isthmic PTC is more often associated with short-term recurrence in the contralateral central compartment, ${ }^{13}$ and approximately a third of patients (32\%) have a serum thyroglobulin concentration of more than $2.0 \mathrm{U} / \mathrm{mL}$ after postoperative iodine-131 remnant ablation. ${ }^{12}$

Strengths of this study include the prospective design, the homogeneity of the participants, and its high practical value because of the involvement of bilateral paratracheal LNM. Limitations are the short follow-up time to assess outcomes and the lack of investigations into mechanisms that might explain findings. As reported by Conzo et al, ${ }^{29}$ the effect of CND in PTC on survival and recurrence is controversial. Additional long-term perspective studies are 
therefore needed to further analyze outcomes and clarify the LNM mechanism of isthmic PTC, which may involve epithelial-mesenchymal transition related to the unique anatomy and blood supply of the isthmus location within the thyroid.

\section{Conclusions}

Because of its unique anatomic location, isthmic PTC differs from PTC in the thyroid lobes with respect to pretracheal and bilateral paratracheal LNM, even in patients of comparable age, sex, tumor size, ETE, $B R A F$ mutation, and pTNM staging. The isthmus location was found to be an independent risk factor for bilateral paratracheal LNM. This information may contribute to the development of an appropriate surgical protocol for isthmic PTC.

\section{Abbreviations}

CND, Central neck dissection; ETE, Extrathyroidal extension; LNM, Lymph node metastasis; PTC, Papillary thyroid cancer; pTNM, Pathologic TNM; cN0, Clinically node-negative; $\mathrm{cN} 1$, Clinically node-positive.

\section{Disclosure}

The authors report no conflicts of interest in this work.

\section{References}

1. Gilmartin A, Ryan M. Incidence of thyroid cancer among patients with thyroid nodules. Ir Med J. 2018;111(8):802.

2. Park JP, Roh JL, Lee JH, et al. Risk factors for central neck lymph node metastasis of clinically noninvasive, node-negative papillary thyroid microcarcinoma. Am J Surg. 2014;208(3):412-418. doi:10.10 16/j.amjsurg.2013.10.032

3. Haugen BR, Alexander EK, Bible KC, et al. 2015 American Thyroid Association management guidelines for adult patients with thyroid nodules and differentiated thyroid cancer: the American Thyroid Association guidelines task force on thyroid nodules and differentiated thyroid cancer. Thyroid. 2016;26(1):1-133. doi:10.1089/thy.2015.0020

4. Asare EA, Wang TS. Comparative effectiveness in thyroid cancer: key questions and how to answer them. Cancer Treat Res. 2015;164:67-87.

5. Lim ST, Jeon YW, Suh YJ. Correlation between surgical extent and prognosis in node-negative, early-stage papillary thyroid carcinoma originating in the isthmus. World J Surg. 2016;40(2):344-349. doi:10. 1007/s00268-015-3259-2

6. Chang YW, Lee HY, Kim HS, Kim HY, Lee JB, Son GS. Extent of central lymph node dissection for papillary thyroid carcinoma in the isthmus. Ann Surg Treat Res. 2018;94(5):229-234. doi:10.4174/astr.20 18.94.5.229

7. Nixon IJ, Palmer FL, Whitcher MM, et al. Thyroid isthmusectomy for well-differentiated thyroid cancer. Ann Surg Oncol. 2011;18(3):76 7-770. doi:10.1245/s10434-010-1358-8

8. Su HK, Wenig BM, Haser GC, et al. Inter-observer variation in the pathologic identification of minimal extrathyroidal extension in papillary thyroid carcinoma. Thyroid. 2016;26(4):512-517. doi:10.1089/ thy. 2015.0508
9. Mete O, Rotstein L, Asa SL. Controversies in thyroid pathology: thyroid capsule invasion and extrathyroidal extension. Ann Surg Oncol. 2010;17(2):386-391. doi:10.1245/s10434-0090832-7

10. Vasileiadis I, Boutzios G, Karalaki M, Misiakos E, Karatzas T. Papillary thyroid carcinoma of the isthmus: total thyroidectomy or isthmusectomy? Am J Surg. 2018;216(1):135-139. doi:10.1016/j. amjsurg.2017.09.008

11. Wang J, Sun H, Gao L, Xie L, Cai X. Evaluation of thyroid isthmusectomy as a potential treatment for papillary thyroid carcinoma limited to the isthmus: a clinical study of 73 patients. Head Neck. 2016;38(Suppl 1):E1510-E1514. doi:10.1002/hed.24270

12. Lee YS, Jeong JJ, Nam KH, Chung WY, Chang HS, Park CS. Papillary carcinoma located in the thyroid isthmus. World J Surg. 2010;34(1):36-39. doi:10.1007/s00268-009-0298-6

13. Chai YJ, Kim SJ, Choi JY, Koo Do H, Lee KE, Youn YK. Papillary thyroid carcinoma located in the isthmus or upper third is associated with delphian lymph node metastasis. World J Surg. 2014;38 (6):1306-1311. doi:10.1007/s00268-013-2406-x

14. Li G, Lei J, Peng Q, et al. Lymph node metastasis characteristics of papillary thyroid carcinoma located in the isthmus: a single-center analysis. Medicine (Baltimore). 2017;96(24):e7143. doi:10.1097/ MD.0000000000007143

15. Koo BS, Choi EC, Yoon YH, Kim DH, Kim EH, Lim YC. Predictive factors for ipsilateral or contralateral central lymph node metastasis in unilateral papillary thyroid carcinoma. Ann Surg. 2009;249 (5):840-844. doi:10.1097/SLA.0b013e3181a40919

16. Orloff LA, Kuppersmith RB. American Thyroid Association's central neck dissection terminology and classification for thyroid cancer consensus statement. Otolaryngol Head Neck Surg. 2010;142 (1):4-5. doi:10.1016/j.otohns.2009.11.013

17. Haglund F, Garvin S, Ihre-Lundgren C, et al. Detailed lymph node sectioning of papillary thyroid carcinoma specimen increases the number of pN1a patients. Endocr Pathol. 2016;27(4):346-351. doi:10.1007/s12022-016-9438-3

18. Jeon YW, Ahn YE, Chung WS, Choi HJ, Suh YJ. Radioactive iodine treatment for node negative papillary thyroid cancer with capsular invasion only: results of a large retrospective study. Asia Pac J Clin Oncol. 2016;12(1):e167-e173. doi:10.1111/ajco.12159

19. Nam SH, Bae MR, Roh JL, et al. A comparison of the 7th and 8th editions of the AJCC staging system in terms of predicting recurrence and survival in patients with papillary thyroid carcinoma. Oral Oncol. 2018;87:158-164. doi:10.1016/j.oraloncology.2018.11. 003

20. Pontieri G, Urselli F, Peschi L, et al. Is the isthmus location an additional risk factor for indeterminate thyroid nodules? Case report and review of the literature. Front Endocrinol (Lausanne). 2018;9:750. doi:10.3389/fendo.2018.00750

21. Jin BJ, Kim MK, Ji YB, Song CM, Park JH, Tae K. Characteristics and significance of minimal and maximal extrathyroidal extension in papillary thyroid carcinoma. Oral Oncol. 2015;51(8):759-763. doi:10.1016/j.oraloncology.2015.05.010

22. Karatzas T, Charitoudis G, Vasileiadis D, Kapetanakis S, Vasileiadis I. Surgical treatment for dominant malignant nodules of the isthmus of the thyroid gland: a case control study. Int J Surg. 2015;18:64-68. doi:10.1016/j.ijsu.2015.04.039

23. Li G, Li R, Song L, et al. Implications of extrathyroidal extension invading only the strap muscles in papillary thyroid carcinomas. Thyroid. 2020;30(1):57-64. doi:10.1089/thy.2018.0801

24. Goldfarb M, Rodgers SS, Lew J. Appropriate surgical procedure for dominant thyroid nodules of the isthmus $1 \mathrm{~cm}$ or larger. Arch Surg. 2012;147(9):881-884. doi:10.1001/archsurg.2012.728

25. Song CM, Lee DW, Ji YB, Jeong JH, Park JH, Tae K. Frequency and pattern of central lymph node metastasis in papillary carcinoma of the thyroid isthmus. Head Neck. 2016;38(Suppl 1):E412-E416. doi:10.10 02/hed.24009 
26. Lee YC, Shin SY, Kwon KH, Eun YG. Incidence and clinical characteristics of prelaryngeal lymph node metastasis in papillary thyroid cancer. Eur Arch Otorhinolaryngol. 2013;270(9):2547-2550. doi:10. 1007/s00405-013-2471-7

27. Ramundo V, Lamartina L, Falcone R, et al. Is thyroid nodule location associated with malignancy risk? Ultrasonography. 2019;38(3):23 1-235. doi:10.14366/usg.18050
28. Zhang TT, Qi XZ, Chen JP, et al. The association between tumor's location and cervical lymph nodes metastasis in papillary thyroid cancer. Gland Surg. 2019;8(5):557-568. doi:10.21037/gs.2019.10.02

29. Conzo G, Polistena A, Calò PG, et al. Efficacy of combined treatment for anaplastic thyroid carcinoma: results of a multinstitutional retrospective analysis. Int J Surg. 2014;12(Suppl 1):S178-82. doi:10.10 16/j.ijsu.2014.05.015

\section{Publish your work in this journal}

Cancer Management and Research is an international, peer-reviewed open access journal focusing on cancer research and the optimal use of preventative and integrated treatment interventions to achieve improved outcomes, enhanced survival and quality of life for the cancer patient.
The manuscript management system is completely online and includes a very quick and fair peer-review system, which is all easy to use. Visit http://www.dovepress.com/testimonials.php to read real quotes from published authors. 